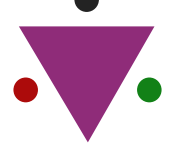

IJCRR

Section: Healthcare

Sci. Journal Impact

Factor: 6.1 (2018)

ICV: 90.90 (2018)

(c) (1) (3)

Copyright@IJCRR

\section{Physical Activity and Dietary Habits among MBBS Students of a Private Medical College of Eastern India}

\author{
Ria Ganguly ${ }^{1}$, Lipilekha Patnaik ${ }^{2}$, Sumitra Pattanaik ${ }^{3}$, Trilochan Sahu ${ }^{4}$ \\ 'PG Resident, Community Medicine, IMS and SUM Hospital, Siksha 'O' Anusandhan Deemed to be University, Bhubaneswar, India; \\ 2Professor, Community Medicine, IMS and SUM Hospital, Siksha 'O' Anusandhan Deemed to be University, Bhubaneswar, India; 3Professor, \\ Community Medicine, IMS and SUM Hospital, Siksha 'O' Anusandhan Deemed to be University, Bhubaneswar, India; 'Professor \& Head, \\ Community Medicine, IMS and SUM Hospital, Siksha 'O' Anusandhan Deemed to be University, Bhubaneswar, India.
}

\title{
ABSTRACT
}

Background: Physical activity and dietary habits play a major role in the prevention of non-communicable diseases. The stress involved in meeting the responsibilities of becoming a physician may adversely affect the exercise and dietary habits of students.

Objectives: To assess the practice of physical activity and dietary habits amongMBBS students of a private Medical College of Eastern India.

Materials and Methods: A cross-sectional study was conducted from July-September 2018 among 130 MBBS students a private Medical College of Eastern India. Physical activity was assessed by using the Global Physical Activity Questionnaire (GPAQ) and dietary habits by a pretested and pre-structured questionnaire. Data were entered into an excel spreadsheet and analysed by SPSS software version 20.

Results: Mean age of study participants was $21.99 \pm 0.96$ years. About $55.4 \%$ were females, $93.1 \%$ were Hindus and $92.3 \%$ belonged to general caste. According to WHO criteria for obesity, $28.5 \%$ were overweight and $11.5 \%$ were obese. The median total energy expenditure was 599.01 metabolic equivalent-min/week (IQR-420-780). Normal-weight/ underweight students were more likely to be achieving recommended physical activity (PA) levels than overweight/ obese participants based on overall MET value and this difference was statistically significant $(p=0.003) .40 .8 \%$ of students were not physically active. About $19 \%$ were not involved in any activity at leisure, $61.2 \%$ thought they were overweight. Among them, $65.4 \%$ practised various exercise to maintain a healthy weight.

Conclusion: Promotion of physical activity by increasing awareness and specific intervention for obese students is needed for obesity control.

Key Words: Physical activity, MET value, Global physical activity questionnaire, Undergraduate students

\section{INTRODUCTION}

Physical activity is defined by World Health Organization as "any bodily movement produced by skeletal muscles that need energy expenditure including activities undertaken while working, playing, completing household chores, travelling, and engaging in recreational pursuits." Thus, physical activity shouldn't be confused with "exercise", which may be a subcategory of that's planned, structured, repetitive, and aims to enhance or maintain one or more components of physical fitness. ${ }^{1}$ Both moderate and vigorous-intensity physical activity improve health. Insufficient physical activity is a key risk factor for non-communicable diseases (NCDs) like cardiovascular diseases, cancer and diabetes. Approximately two-billion people aged 18 years and above are overweight, and more than half a billion are obese. ${ }^{2}$ Inadequate physical activity and unhealthy dietary habits are among the factors contributing to the increasing number of the overweight and obese population. ${ }^{1}$ The trend must be addressed as it contributes to the development of cardiovascular disease and its risk factors, which increases the burden on the economy and contributes toward psychosocial consequences. ${ }^{3}$

Globally, 1 in 4 adults are not active enough and about $80 \%$ of the world's adolescent population is insufficiently physically active. WHO the Member States have agreed to scale

\section{Corresponding Author:}

Lipilekha Patnaik, Department of Community Medicine, Institute of Medical Sciences \& SUM Hospital, Siksha 'O' Anusandhan Deemed to be University, Bhubaneswar, India; Phone: 919437322268; Email: drlipilekha@yahoo.co.in

ISSN: 2231-2196 (Print)

Received: 26.06 .2020
ISSN: 0975-5241 (Online)

Revised: 18.08 .2020
Accepted: 13.10 .2020
Published: 12.11 .2020 
back insufficient physical activity by $10 \%$ by 2025 . WHO recommends adults aged 18-64 years should engage in at least 150 minutes of moderate-intensity physical activity throughout the week, or do at least 75 minutes of vigorous-intensity physical activity throughout the week, or the same combination of moderate and vigorous-intensity activity. For further health benefits, moderate-intensity physical activity should be increased to 300 minutes per week or equivalent for adults. Muscle-strengthening activities involving major muscle group should be done for two or more days every week. Benefits of regular physical activity of moderate intensity at all ages outweigh the potential harm. Improved muscular and cardiorespiratory fitness; bone and functional health; reduction of risk of hypertension, coronary heart disease, stroke, diabetes, various types of cancer (including breast cancer and colon cancer), and depression are major benefits of adequate physical activity. ${ }^{4,5}$

Insufficient physical activity is one among the leading risk factors for global mortality and is on the increase in many countries, adding to the burden of NCDs and affecting general health worldwide. Insufficiently active people have a $20 \%$ to $30 \%$ increased risk of death compared to sufficiently active people. Insufficient physical activity is very common in medical students since they are burdened with a busy schedule of classes, exams and clinical postings and less free time. It is very difficult to exercise regularly; many also tend to ignore their health and indulge in unhealthy dietary practices. Angyan et al. reported that medical students had low physical activity levels as a result of high workload and less free time. ${ }^{6}$ It is observed that medical students have sufficient knowledge about the benefits of physical activity but the practice of a physical activity is inadequate in real life. During University and college years the students get an opportunity for learning about healthy lifestyle and enhancing nutritional awareness. As health care professionals, it is presumed that medical students have substantial knowledge about physical activity and its benefits and might have an influence on their patients' attitude towards the need for a regular physical activity program and an obligation to prescribe suitable exercises. Few studies show that there is a direct correlation between physical activity level in medical students and the counselling or medical advice they provide to their patients. ${ }^{7,8,9,10} \mathrm{It}$ is also seen that medical students have a fair knowledge about healthy dietary practices. In contrary studies have shown that medical students especially who stay in hostels away from their home are susceptible to irregular dietary habits, lack of exercise, and addiction. ${ }^{10,11}$ So the study was planned to assess the practice of physical activity and dietary habits among MBBS students of a private medical college.

\section{MATERIALS AND METHODS}

This was a cross-sectional study conducted in 3 months duration from July - September 2018 among $7^{\text {th }}$ Semester MBBS students of a private medical college of Odisha. All students present in the class during the survey were included in the study after taking informed written consent. Total of 130 students participated in the study. A pre-designed \& pre-tested questionnaire was used which included sociodemographic characteristics, Global Physical Activity Questionnaire(GPAQ) and questions related to their dietary practices were included in the questionnaire.

Global Physical Activity Questionnaire (GPAQ) measures physical activity in adults. This questionnaire helps to monitor insufficient physical activity as one of the main noncommunicable diseases risk factors.GPAQ is a self-reported questionnaire which had three domains: activities at work, travelling activities and recreational activities. The energy use of each PA domain was calculated as metabolic equivalent (MET)-min/week. There are different levels of physical activity assigned by the GPAQ creators that consist of low, moderate and high physical activity levels.

GPAQ Total of greater than or equal to $3000 \mathrm{MET}$ min/week - High Category

GPAQ Total ranging from 600-2999 MET minutes/week Moderate Category

GPAQ Total below 600 MET minutes/week - Low Category

The metabolic equivalent MET-minutes/week $\geq 600$ is considered as the recommended levels of physical activity by WHO.

For the calculation of physical activity, the following MET values are used:

\begin{tabular}{|c|c|}
\hline Work & $\begin{array}{l}\text { Moderate MET value }=4.0 \\
\text { Vigorous } M E T \text { value }=8.0\end{array}$ \\
\hline Transport & Cycling and walking MET value $=4.0$ \\
\hline Recreation & Moderate MET value $=4.0$ \\
\hline Vigorous & MET value $=8.0$ \\
\hline
\end{tabular}

Total physical activity MET-minutes/week which was the sum of the total MET minutes of activity computed for each setting. Anthropometric measurements like height and weight were taken and BMI was calculated using the formula weight in kilograms/height in metre square and categorized as per WHO criteria. ${ }^{2}$

\section{Data analysis}

Data were analysed by SPSS software version 20.0 licensed to the institute. The baseline characteristics of the participants were reported as frequency, percentage, mean and 
standard deviation. Univariate analysis of the associations between the BMI, gender, dietary habits, minutes of sedentary activity with the recommended levels of physical activity was analysed by using the Pearson's chi-square, Fisher's exact test and unpaired t-test, if appropriate. The associations were considered statistically significant when $\mathrm{P}<0.05$.

\section{RESULTS}

In the present study, the mean age of the students was 21.99 \pm 0.96 . Majority (55.4\%) of the students were female, $93.1 \%$ were Hindus, $92.3 \%$ from general caste, $96.1 \%$ from the urban residence. The majority $(83.1 \%)$ were from nuclear family and $80.8 \%$ were staying in the hostel. (Table 1)

According to WHO classification of MET $59.2 \%$ of the students were physically active while $40.8 \%$ were not physically active. (Figure 1) In the study, $84.6 \%$ responded that they do moderate activity in college and nobody was involved in vigorous activity at college. $25.4 \%$ involved in vigorous activity and $44.6 \%$ in moderate activity at leisure. $66.9 \%$ walk to commute to college. (Figure 2) Mean MET value of the students was $599.01 \pm 253$.

According to WHO criteria for obesity, $48.5 \%$ of students were having normal BMI, $11.5 \%$ were in undernutrition category, $28.5 \%$ were overweight and $11.5 \%$ were obese. In the present study, $34.6 \%$ of the students did not adopt any weight-loss method, $23.8 \%$ does exercise and $14.6 \%$ goes to the gym, followed by other methods like control diet, jogging, swimming and engaging in some sports.

Mean sedentary minutes per day was $411.23 \pm 52.35 \mathrm{~min} /$ day. Mean sedentary minutes per day was significantly higher among males ( $423 \pm 60.96 \mathrm{~min} /$ day) than females (401.67 \pm 42.29) $(\mathrm{P}=0.024)$ (Table 2). Mean sedentary minutes per day among students with MET $>600$ was $413.21 \pm 46.56$ and $409.87 \pm 56.25$ among students with MET $<600$, the difference was not statistically significant $(\mathrm{P}=0.72)$.

It was observed that $60.3 \%$ of male students and $58.3 \%$ of the female students met the WHO recommendation of $>600$ MET. Though this difference was not statistically significant across gender. Those taking non-vegetarian diet were significantly higher physically active than those who were vegetarian $(\mathrm{P}=0.004)$. Students with normal/ low BMI were doing significantly higher physical activity. It was also seen that students with a BMI $>25$ i.e students who are overweight/ obese were less physically active than those with BMI $<25$ and the difference was statistically significant $(\mathrm{P}=0.003)$. (Table 3) In binary logistic regression, those who were taking non-veg diet was 3.05 times higher odds of being physically active than vegetarians and those who were normal/underweight were 3.092 times higher odds of being physically active than overweight/ obese students. (Table 4)
Majority of the students had a mixed type of diet and most $(55 \%)$ of them told chicken as their favourite non-veg item followed by fish, prawn, crab and egg. Students who were eating junk $>1$ time a week were significantly higher overweight/obese than taking junk food rarely $(\mathrm{P}=0.09)$. $61.2 \%$ of the students perceived their obesity status correctly and self-perception of obesity was significantly associated with BMI $(\mathrm{P}=0.00)$. Those who were eating outside food were significantly higher overweight/obese (45\%) than those eating in hostel/home (27\%) $(\mathrm{P}=0.04)$.

\section{DISCUSSION}

In the present study, level of physical activity among the third-year medical students meeting WHO recommendation for physical activity was $59.2 \%$ while $40.8 \%$ students did not meet WHO recommendations. This may be due to their daily hectic academic schedule in college. These students should be encouraged to improve their physical activity level through recreational activities. A study by Cocca et al. showed that, $60 \%$ did not meet recommended PA levels in undergraduate students from Granada (Southern Spain). ${ }^{12}$ Varela-Mato et al. also reported $72.6 \%$ did not meet recommended PA levels among undergraduate students in Vigo (Northern Spain). ${ }^{13}$ The variation in the level of physical activity among different studies can be attributed to the usage of different criteria for assessing the physical activity and also due to the urbanisation and very rapid change in lifestyle over a decade. A recent study showed that the level of physical activity among physicians, who regularly worked in the clinical practice, was low (only $31.6 \%$ are physically active). ${ }^{14}$ Previous studies showed medical students were more physically active than the general populations, and more than two-thirds of medical students met the recommended levels of PA. ${ }^{15-17}$ Each medical college have different characteristics, while some might have PA-friendly environment some colleges might lack such facilities which might be the reason for various levels of PA. $60.3 \%$ of male students and $58.3 \%$ of the female students met the WHO recommendation of $>600$ MET in our study. The difference was not statistically significant which may be attributed to the same academic schedule an equal awareness about the benefits of physical activity among medical students. Overall inactivity levels were $12.6 \%$ in males and $18.9 \%$ in females in a study by Shah et al. in 2005 in six regions of India. ${ }^{18}$ Prevalence of physical inactivity among male and females was $38.8 \%$ and $46.1 \%$ respectively, found in a multicentric study done in 11 cities of India in 2014. ${ }^{19}$

Our study has demonstrated a higher level of moderate physical activity in leisure time and transport than during work. This is because medical students have a sedentary lifestyle and mostly involves attending classes and clinical postings the whole day. Thus, the students meet their requirement of 
physical activity through recreational or leisure activities. In other studies, done in the general population, the proportion of people involving in recreational or leisure activities were very low. ${ }^{20-22}$ Similar pattern was also seen in a study done in rural India. ${ }^{23}$ It is well known that the risk of noncommunicable diseases increases with increase in the duration of sedentary behaviour. ${ }^{24-26}$ The present study has shown mean sedentary minutes per day was $411.23 \pm 52.35 \mathrm{~min} /$ day. Mean sedentary minutes per day among students with MET $>600$ was $413.21 \pm 46.56$ and $409.87 \pm 56.25$ among students with MET $<600$, the difference was not statistically significant. This is consistent with previous studies showing that time spent on sedentary activities such as using a computer or watching TV or using social media is negatively correlated with volumes of moderate and vigorous physical activity. ${ }^{27,28}$

This study showed that $43.1 \%$ of the overweight/obese and $69.6 \%$ of the under/normal weight met the recommended physical activity/MET value. Thus normal-weight or underweight students were achieved recommended level of physical activity than overweight/ obese participants based on overall MET value and this difference was statistically significant which are in line with previous studies. ${ }^{29,30}$ showed similar results. They reported that normal-weight participants were more likely to be achieving recommended PA levels but not overweight participants. The present study identified that the students gave priority to academics, which was considered more important than participating in regular PA. The stress of academics may be one of the barriers to PA by the students. Our findings explained that medical students spend a lot of time in the daily clinical postings and lectures which is tiring for them. It is mentioned in a study that the stressful nature of medical training might be a reason for reduced PA in medical students. ${ }^{15}$ Thus PA should be promoted in medical colleges because evidence shows that clinicians were more active before starting MBBS and it would be late to promote PA after medical students graduate. In our study it is observed that those who had a non-veg diet were found to be physically active, students who were eating junk $>1$ time a week were overweight/obese. Majority of the students perceived their obesity status correctly. Several studies conducted to evaluate the physical activity, diet, and fitness status of university students have revealed that the physical condition and dietary habits of students are associated with their attitudes toward fitness. Positive attitudes toward physical fitness are vital for future health care professionals. ${ }^{31,32}$

\section{CONCLUSION}

There is a need to encourage physical activity and healthy dietary habits in medical colleges, so that budding physician will be the role models and able to advise their patients regarding healthy lifestyle practices. Experimental studies for promotion of healthy lifestyle and prevention of obesity among undergraduate students are needed.

Limitation: The findings of this study cannot be generalized as it was done among one batch of MBBS students and by self-administered questionnaire.

\section{ACKNOWLEDGEMENT}

We are extremely thankful to MBBS students who participated and co-operated whole-heartedly during this research. Authors acknowledge the immense help received from the scholars whose articles are cited and included in references to this manuscript. The authors are also grateful to authors/ editors/publishers of all those articles, journals and books from where the literature for this article has been reviewed and discussed.

\section{Financial Support: None}

Conflict of Interest: On behalf of all authors, the corresponding author states that there is no conflict of interest.

\section{REFERENCES}

1. WHO Physical Activity. Available from http://www.who.int/dietphysicalactivity/pa/en/ Accessed date, August 2020.

2. Obesity and overweight - World Health Organization. Available from: https://www.who.int/news-room/fact-sheets/detail/obesity-and-overweigh/ Accessed date, August 2020.

3. Fuster V. Epidemiology of Cardiovascular Disease - Promoting Cardiovascular Health in the Developing World - NCBI Bookshelf [Internet]. NCBI Bookshelf. 2010;1-199.

4. Silvestri L. Benefits of physical activity. Percept Mot Skills [Internet]. 1997;84(3 PART I):890.

5. Strzyzewski S. Physical activity. Pieleg Polozna [Internet]. 1973;1:6-7. Available from: https://www.who.int/news-room/ fact-sheets/detail/physical-activity

6. Ángyán L, Téczely T, Mezey B, Lelovics Z. Selected Physical Characteristics of Medical Students. Med Educ Online. 2003 Dec;8(1):4328.

7. Lobelo F, Duperly J, Frank E. Physical activity habits of doctors and medical students influence their counselling practices. Br J Sports Med. 2009; 43(2):89-92.

8. Frank E, Galuska DA, Elon LK, Wright EH. Personal and clinical exercise-related attitudes and behaviours of freshmen U.S. medical students. Res Q Exerc Sport. 2004;75(2):112-121.

9. Stanford FC, Durkin MW, Blair SN, Powell CK, Poston MB, Stallworth JR. Determining levels of physical activity in attending physicians, resident and fellow physicians and medical students in the USA. Br J Sports Med. 2012 Apr;46(5):360-364.

10. Duperly J, Lobelo F, Segura C, Sarmiento F, Herrera D, Sarmiento OL, et al. The association between Colombian medical students' healthy personal habits and a positive attitude toward preventive counselling: Cross-sectional analyses. BMC Public Health. 2009;9:218

11. Gupta S, Ray TG, Saha I. Overweight, obesity and influence of stress on body weight among undergraduate medical students. Ind J Community Med. 2009 Jul 1;34(3):255-257. 
12. Cocca A, Liukkonen J, Mayorga-Vega D, Viciana-Ramírez J. Health-related physical activity levels in Spanish youth and young adults. Percept Mot Skills 2014;118(1):247-260.

13. Varela-Mato V, Cancela JM, Ayan C, Martín V, Molina A. Lifestyle and health among Spanish university students: Differences by gender and academic discipline. Int J Environ Res Public Health 2012;9(8):2728-2741.

14. Al Rashidi FS. Level of Physical Activity of Physicians among Residency Training Program at Prince Sultan Military Medical City, Riyadh, KSA 2014. Int J Health Sci (Qassim). 2016 Mar;10(1):39-46.

15. Wattanapisit A, Fungthongcharoen K, Saengow U, Vijitpongjinda S. Physical activity among medical students in Southern Thailand: A mixed-methods study. BMJ Open. 2016 Sep 1;6(9): e013479.

16. Stanford FC, Durkin MW, Stallworth JR, Blair SN. Comparison of physical activity levels in physicians and medical students with the general adult population of the United States. Phys Sports med. 2013;41(4):86-92.

17. Wattanapisit A. Ganesan T, Anothaisintawee T. Prevalence of Physical Activity and Associated Factors of Medium and High Activity among Medical Students at Ramathibodi Hospital 2015; 10.13140 .

18. Shah B. Development of Sentinel Health Monitoring Centers for Surveillance of Risk Factors of Noncommunicable Diseases in India. 2005:1-71.

19. Anjana RM, Pradeepa R, Das AK, Deepa M, Bhansali A, Joshi $\mathrm{SR}$, et al. Physical activity and inactivity patterns in India - results from the ICMR-INDIA B study (Phase-1) [ICMR-INDIAB-5]. Int J Behav Nutr Phys Act 2014;11(1):26.

20. Muntrer P, Gu D, Wildman RP, Chen J, Qan W, Whelton PK, et al. Prevalence of physical activity among Chinese adults: Results from the International Collaborative Study of Cardiovascular Disease in Asia. Am J Public Health. 2005;95(9):1631-1636.

21. Dias-da-Costa JS, Hallal PC, Wells JCK, Daltoé T, Fuchs SC, Menezes AMB, et al. Epidemiology of leisure-time physical activity: a population-based study in southern Brazil. Cad saúde pública / Ministério da Saúde, Fundação Oswaldo Cruz, Esc Nac Saúde Pública. 2005;21(1):275-282.
22. Trinh OTH, Nguyen ND, Dibley MJ, Phongsavan P, Bauman AE. The prevalence and correlates of physical inactivity among adults in Ho Chi Minh City. BMC Public Health. 2008;8:204.

23. Devamani C, Oommen A, Mini G, Abraham V, George K. Levels of physical inactivity in rural and urban Tamil Nadu, India: A cross-sectional study. J Clin Prev Cardiol. 2019;8(1):13.

24. Tcymbal A, Andreasyan D, Whiting S, Mikkelsen B, Rakovac I, Breda J. Prevalence of Physical Inactivity and Sedentary Behavior Among Adults in Armenia. Front Public Heal [Internet]. 2020 May 5;8:157.

25. Sarma PS, Sadanandan R, Thulaseedharan JV, Soman B, Srinivasan K, Varma RP, et al. Prevalence of risk factors of non-communicable diseases in Kerala, India: Results of a cross-sectional study. BMJ Open. 2019;9(11):e027880.

26. Gonzalez K, Fuentes J, Márquez JL. Physical inactivity, sedentary behaviour and chronic diseases. Korean J Fam Med. 2017;38(3):111-115.

27. O'Brien W, Issartel J, Belton S. Relationship between Physical Activity, Screen Time and Weight Status among Young Adolescents. Sports 2018;6(3):57.

28. Janssen X, Martin A, Hughes AR, Hill CM, Kotronoulas G, Hesketh KR. Associations of screen time, sedentary time and physical activity with sleep in under $5 \mathrm{~s}$ : A systematic review and meta-analysis. Sleep Med Rev 2020; 49: 101226.

29. Meseguer CM, Galán I, Herruzo R, Zorrill B, Rodríguez-Artalejo F. Leisure-Time Physical Activity in a Southern European Mediterranean Country: Adherence to Recommendations and Determining Factors. Rev Española Cardiol. 2009;62(10):11251133.

30. Loyen A, Clarke-Cornwell AM, Anderssen SA, Hagströmer M, Sardinha LB, Sundquist K, et al. Sedentary Time and Physical Activity Surveillance Through Accelerometer Pooling in Four European Countries. Sport Med. 2017 Jul 1;47(7):1421-1435.

31. Kashani IA, Kaplan RM, Criqui MH, Nader PR, Rupp J, Sallis JF, et al. Cardiovascular risk factor assessment of medical students as an educational tool. Am J Prev Med. 1992;8(6):384388.

32. Angyan L. Promoting physical activity in medical education: Mini-review. Acta Physiologica Hungarica. 2004; 91(2)157166.

\section{Table 1: Sociodemographic characteristic of the students}

\begin{tabular}{|c|c|c|}
\hline \multicolumn{2}{|l|}{ Variables } & \multirow{2}{*}{$\begin{array}{c}\text { Number (Percentage) } \\
58(44.6)\end{array}$} \\
\hline Gender & Male & \\
\hline \multirow{3}{*}{ Religion } & Female & $72(55.4)$ \\
\hline & Hindu & $121(93.1)$ \\
\hline & Muslim & $6(4.6)$ \\
\hline \multirow{5}{*}{ Caste } & Christian & $2(1.5)$ \\
\hline & Others & $1(0.8)$ \\
\hline & General & $120(92.3)$ \\
\hline & SC & $7(5.4)$ \\
\hline & ST & $3(2.3)$ \\
\hline
\end{tabular}


Table 1: (Continued)

Variables

Residence

Family type

Residence

\section{Number (Percentage)}

$\begin{array}{lc}\text { Urban } & 125(96.1) \\ \text { Rural } & 4(3.07) \\ \text { Tribal } & 1(0.8) \\ \text { Joint } & 22(16.9) \\ \text { Nuclear } & 108(83.1) \\ \text { Home } & 25(19.2) \\ \text { Hostel } & 105(80.8)\end{array}$

Table 2: Association of mean sedentary min/day with Gender

\begin{tabular}{lccc} 
Gender & N & Mean sedentary min/day & p value \\
Male & 58 & $423.1 \pm 60.96$ & 0.024 \\
Female & 72 & $401.67 \pm 42.29$ & \\
\hline
\end{tabular}

Table 3: Association of physical activity with gender, type of diet and obesity

\begin{tabular}{|c|c|c|c|}
\hline Variables & $<600 \mathrm{MET}$ & $>600$ MET & Pvalue \\
\hline \multicolumn{4}{|l|}{ Gender } \\
\hline Male & $23(39.7 \%)$ & $35(60.3 \%)$ & \multirow{2}{*}{0.817} \\
\hline Female & $30(41.7 \%)$ & $42(58.3 \%)$ & \\
\hline \multicolumn{4}{|l|}{ Diet } \\
\hline Veg & $15(68.2 \%)$ & $7(31.8 \%)$ & \multirow{2}{*}{0.004} \\
\hline Non veg & $38(35.2 \%)$ & $70(64.8 \%)$ & \\
\hline \multicolumn{4}{|l|}{ Obesity status } \\
\hline $\begin{array}{l}\text { Normal/ Underweight } \\
\left(<25 \mathrm{~kg} / \mathrm{m}^{2}\right)\end{array}$ & $24(30.4 \%)$ & $55(69.6 \%)$ & \multirow{2}{*}{0.003} \\
\hline $\begin{array}{l}\text { Overweight/Obese } \\
\left(>25 \mathrm{~kg} / \mathrm{m}^{2}\right)\end{array}$ & $29(56.9 \%)$ & $22(43.1 \%)$ & \\
\hline
\end{tabular}

Table 4: Binary logistic regression of physical activity

Variables

\section{BMI Category}

Normal/ Underweight

$\left(<25 \mathrm{~kg} / \mathrm{m}^{2}\right)$

Overweight/Obese

$\left(>25 \mathrm{~kg} / \mathrm{m}^{2}\right)$

Diet

Non veg

Veg

\section{P value}

3.02

Ref

0.004

3.05

Ref
0.007 


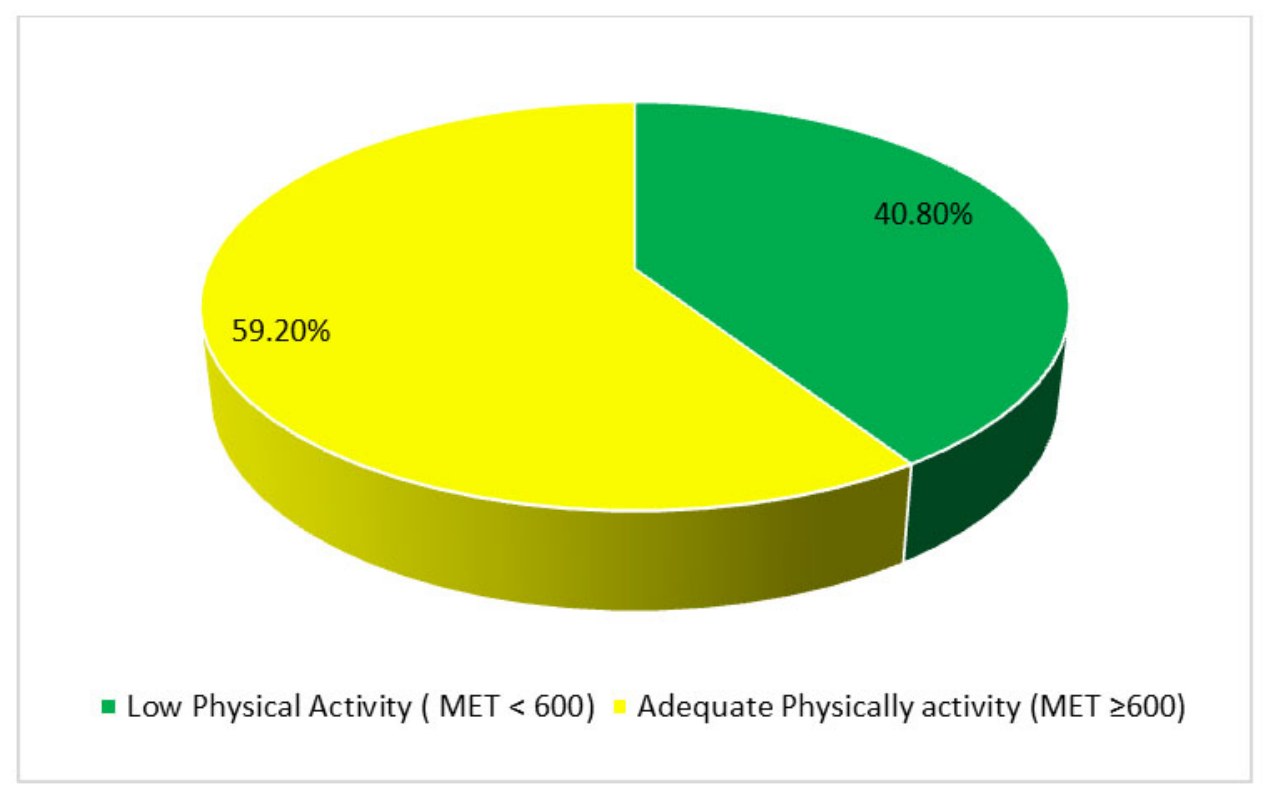

Figure 1: Physical activity according to MET Value.

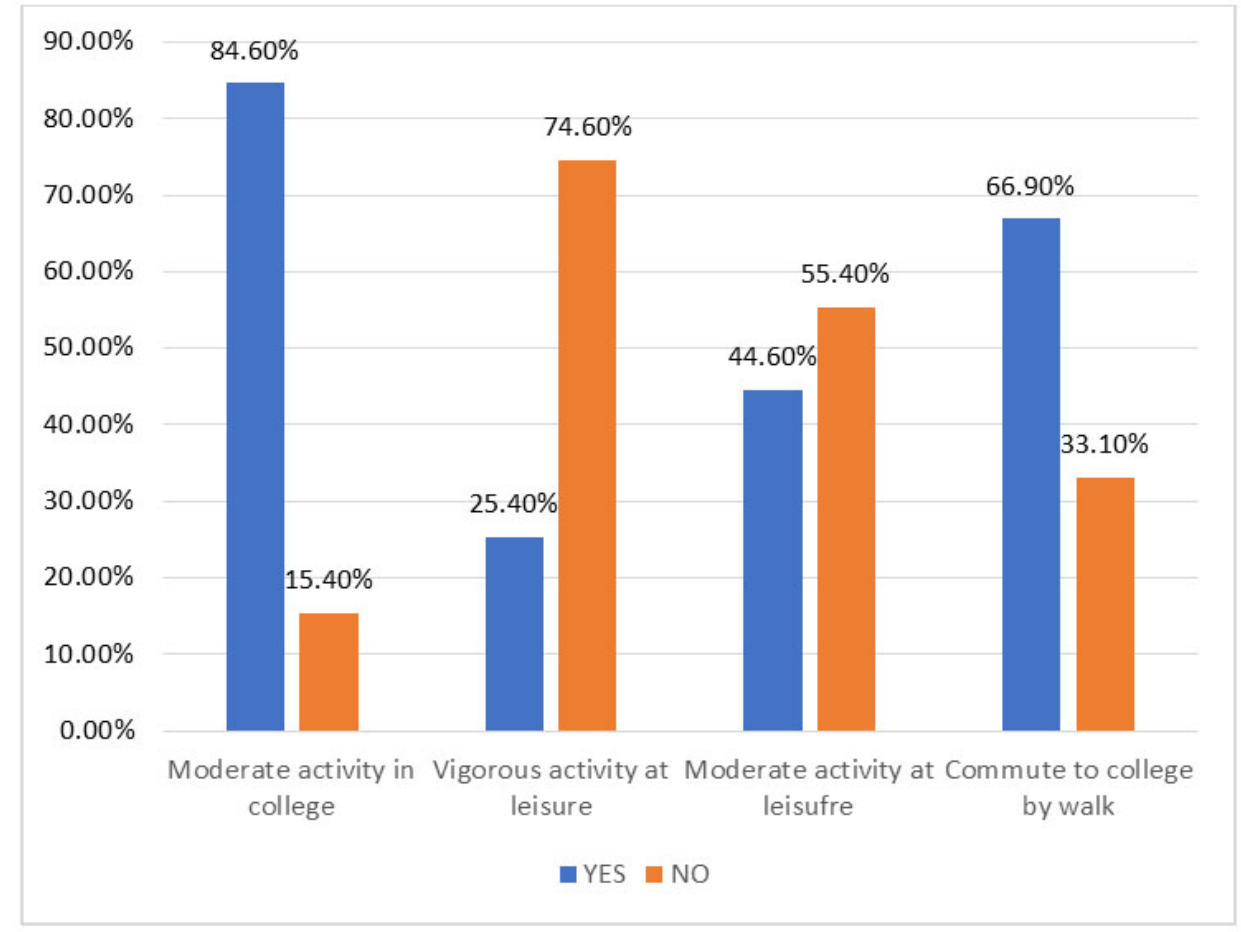

Figure 2: Proportion of students who engage in physical activity by specific domains. 